\title{
An Experimental Investigation into the Effect of Asphalt Binder Modified with SBR Polymer on the Moisture Susceptibility of Asphalt Mixtures
}

\author{
Gholam Hossein Hamedi ${ }^{*}$, Ali Sahraei ${ }^{2}$, Mohammad Hadizadeh Pirbasti ${ }^{1}$ \\ ${ }^{1}$ Department of Civil Engineering, Faculty of Engineering, University of Guilan, P. O. B. 3756, Rasht, Iran \\ 2 Department of Civil Engineering, Faculty of Engineering, Pennsylvania State University, P. O. B. 08102, State Collage, USA \\ * Corresponding author, e-mail: hamedi@guilan.ac.ir
}

Received: 17 June 2020, Accepted: 19 January 2021, Published online: 28 January 2021

\begin{abstract}
There are several experimental methods for improving the moisture strength of asphalt mixtures. Utilization of anti-stripping materials is the most prevalent method. In the present paper, the influence of polymer materials on asphalt binder was investigated using repetitive loading test in wet and dry conditions along with thermodynamic parameters based on the Surface Free Energy components of asphalt binder and aggregates. The results obtained from the present study indicated that using Styrene Butadiene Rubber polymer has improved the asphalt mixtures strength against the moisture damage, especially in the specimens made of granite aggregates. Also, Styrene Butadiene Rubber polymer increased the cohesion free energy and reduced the energy released by the system during the stripping event, which represented a decrease in the tendency for stripping. The stripping percentage index, which is obtained by a combination of the results of the repetitive loading test in wet and dry conditions along with the results of thermodynamic parameters, represented that the specimens made of controlled asphalt binder in the loading cycles under wet conditions had a higher stripping rate. It was also concluded that the modulus loss rate in the control asphalt mixtures was faster than the modified specimens.
\end{abstract}

Keywords

Surface Free Energy, asphalt mixtures, Styrene Butadiene Rubber, moisture damage, repetitive loading

\section{Introduction}

The damage moisture is defined as the displacement of asphalt binder from the surface of the aggregate or the failure of the asphalt binder film is defined moisture damage. This type of damage occurs when aggregates tend to have a greater proportion of water absorption than their tendency to be coated by the asphalt binder $[1,2]$. In addition to moisture damage, the moisture causes different damages such as rutting, fatigue, shoving bleeding, and pothole [3, 4].

The most available experimental studies in the open literature to determine the moisture damage potential in asphalt mixtures, were used to compare the mechanical performance of the mixtures in dry and wet conditions for determination of their susceptibility and the effect of stripping additives. The modified Lottman method (AASHTO T283) is a well-known experimental approach in this field which does not focus on the fundamental properties of materials that are effective in the event of damage and cannot a reason for the weakness or the strength of asphalt mixtures. Also, the results of these tests cannot even provide an appropriate corrective solution for improving the asphalt mixtures performance against the moisture [5]. Accordingly, in the last two decades, many studies have been carried out to use different techniques to determine the moisture susceptibility of asphalt mixtures based on the fundamental properties of materials that affects the asphalt binder cohesion and the asphalt binder-aggregate adhesion.

\subsection{Previous studies}

The primary investigation was reported in Texas Transportation Institute which revealed that Surface Free Energy (SFE) measurements could be applied as an impressive tool to predict moisture damage and fatigue cracking in asphalt mixtures. Hamedi et al. [6] examined the concepts of SFE and its application in asphalt mixtures. The results of his study showed that thermodynamic changed in adhesion and cohesion of SFE were directly related to debonding in the asphalt binder aggregates contact surface and cracks in the mastic. Abandansari and Modarres [7] investigated the 
influence of nanomaterials additives on moisture strength of asphalt mixtures by using the mechanical and thermodynamic methods. Bhasin [8] firstly developed the methods to measure the SFE components of asphalt binder and aggregate. Then, he investigated the relationship between the thermodynamic parameters, which were obtained by measuring the SFE components of asphalt binders and aggregates as well as the moisture susceptibility potential in the asphalt mixtures. Following the previous studies, Howson [9] evaluated using SFE for identification of the resistance of asphalt mixtures against moisture. The experimental results obtained from this study indicated that the modifications made on asphalt binder, had negative or positive influences on the SFE components and adhesion energy. In the study reported by Hamedi and Moghadas Nejad [10], the relationship between the potential of the moisture damage and the thermodynamic parameters was evaluated using the results of susceptibility tests for different asphalt mixture combinations. The results showed that the thermodynamic parameters were significantly associated with the event and severity of moisture damage. In another study, the effect of thermodynamic parameters and mix design on the moisture damage was investigated using statistical analysis. The results showed that the thermodynamic parameters, including the cohesion free energy of asphalt binder, asphalt binder's wettability on the aggregate's surface, the adhesion-free energy of asphalt binder-aggregates and, debonding energy of the system in stripping event could properly predict the moisture susceptibility of different asphalt mixtures [11].

In recent years polymer and nanomaterial have also been utilized to investigate the moisture properties of asphalt mixtures. Changes in the mix design can also slightly affect the strength of the asphalt mixture versus moisture. Accordingly, using anti-stripping additives is the most optimal method to improve the strength of the asphalt mixtures versus moisture. These additives are categorized into two common categories: asphalt binder additives and aggregate additives. Considering the convenience of using asphalt binder additives, the major executive projects which utilize anti-stripping materials have paid attention to this category of additives [12]. Several studies have been carried out on an aggregate modification to improve the strength of the asphalt mixture versus moisture while most of these studies were restricted to experimental studies. Hydrated lime, nano anti-stripping, and liquid anti-stripping additives are the most prevalent anti-stripping materials used in the experimental studies and executive projects.

\subsection{Problem statement and research objectives}

However, the anti-stripping materials that have been used so far, have reduced the moisture damage in asphalt mixtures. This is if the use of these materials is accompanied by a series of executive and technical problems [13]. Therefore, this research has attempted to investigate the use of polymer modifiers. It is worth mentioning that despite the numerous conducted studies on the application of thermodynamic methods in detecting the susceptibility of asphalt mixtures, its use as a tool to determine the susceptibility of different asphalt mixtures and its effects on the anti-stripping mechanism has not yet been widespread. Therefore, this study attempts to obtain the SFE components of the controlled and modified asphalt binder and aggregate. The Styrene Butadiene Rubber (SBR) polymer role on the performance of asphalt mixtures is examined by using thermodynamic concepts. To validate the results of thermodynamic concepts, repetitive loading in dry and wet conditions are carried out on asphalt mixture specimens. The modulus ratio in wet to dry condition is considered as the moisture susceptibility index of different asphalt mixtures. By combining the results of thermodynamic parameters and modulus ratio of wet to dry conditions in different loading cycles, the percentage of asphalt binder stripping from the surface of the aggregate and the moisture damage mechanism is obtained. The most important objectives of the present study can be categorized as follows:

- Studying the influence of SBR polymer on the controlled asphalt binder's SFE components;

- Studying the influence of SBR polymer on thermodynamic parameters including asphalt binder-aggregate adhesion free energy, asphalt binder cohesion free energy, and the system's free energy in the event of stripping;

- Studying the effects of using SBR polymer on the modulus ratio of wet to dry condition in the controlled and modified specimens;

- Comparing the results of the thermodynamic parameters and modulus ratio in wet to dry conditions;

- Combining the results of the thermodynamic parameters and repetitive loading to determine the process of stripping event in the controlled and modified specimens.

\section{Design of an experimental program}

Different experimental procedures were used in the current study as: 
1. Modification of the controlled asphalt binder with SBR polymer in two different percentages

2. Mix design by AASHTO T245 method

3. Implementation of the repetitive loading test on specimens made of controlled and modified asphalt binders

4. Determination of the SFE components of the controlled and modified asphalt binders using Wilhelmy plate and Universal Sorption Device (USD)

5. Calculation of the thermodynamic parameters based on SFE components of asphalt binders, aggregates, and water for various compounds of asphalt mixtures, and

6. Calculation of the percentage of asphalt mixtures' aggregate surface stripping in different loading cycles by combining the results of repetitive loading test and thermodynamic parameters

\subsection{Materials}

\subsubsection{Aggregate}

In the present paper, two different types of granite and limestone aggregates were used, which were acidic and basic, respectively. In fact, the main reason for using these two different aggregates is the different structure of minerals constituting these two types of aggregates, which causes their various susceptibility to moisture damage. The structure of aggregates constituents is evaluated by X-ray fluorescence (XRF) technique. The results of these experiments have been presented in Table 1.

The gradation of aggregates used in the present investigation was the ASTM-standard medium grading to produce dense asphalt mixtures. The nominal size of aggregates in this gradation was $19 \mathrm{~mm}$. The aggregate gradations of two used materials have been illustrated in Fig. 1, whereas the physical properties of these have been documented in Tables 2 and 3.

\subsubsection{SBR polymer}

SBR contains a collection of synthetic rubbers composed of styrene and butadiene. These materials have a suitable strength against wear and ageing. SBR is defined as

Table 1 Structure of minerals forming aggregates used in this study

\begin{tabular}{lcc}
\hline Properties & Limestone & Granite \\
\hline Calcium oxide, $\mathrm{CaO}(\%)$ & 72.47 & 31.75 \\
Magnesium oxide, $\mathrm{MgO}(\%)$ & 2.24 & 2.92 \\
Ferric oxide, $\mathrm{Fe}_{2} \mathrm{O}_{3}(\%)$ & 3.87 & 7.08 \\
Aluminum oxide, $\mathrm{Al}_{2} \mathrm{O}_{3}(\%)$ & 4.84 & 1.74 \\
Silicon dioxide, $\mathrm{SiO}_{2}(\%)$ & 13.58 & 52.19 \\
\hline
\end{tabular}

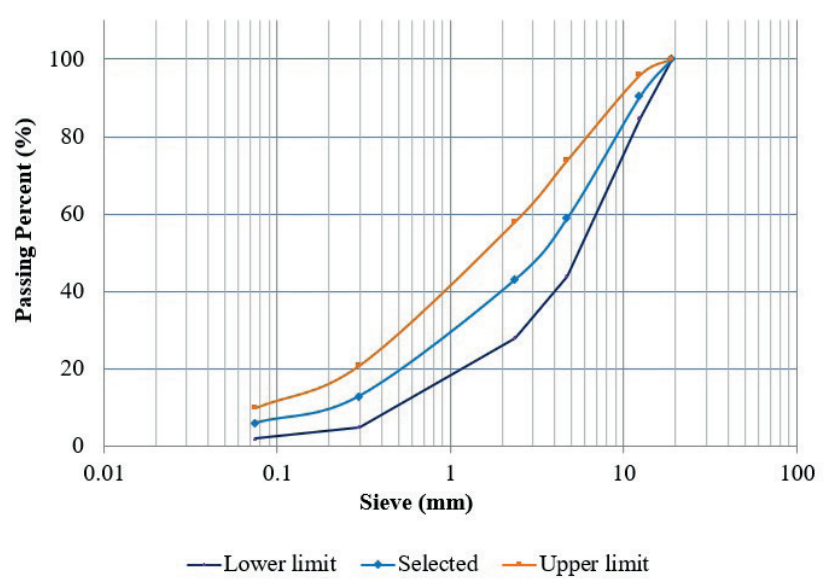

Fig. 1 Gradation of aggregates used in this study

Table 2 Physical properties of aggregates used in this study

\begin{tabular}{|c|c|c|c|c|}
\hline Properties & Standard & Limestone & Granite & $\begin{array}{c}\text { Specification } \\
\text { limit }\end{array}$ \\
\hline Coarse aggregate & \multirow{4}{*}{$\begin{array}{c}\text { ASTM C } \\
127[14]\end{array}$} & & & - \\
\hline $\begin{array}{l}\text { Bulk specific } \\
\text { gravity }\left(\mathrm{g} / \mathrm{cm}^{3}\right)\end{array}$ & & 2.63 & 2.61 & - \\
\hline $\begin{array}{l}\text { SSD specific } \\
\text { gravity }\left(\mathrm{g} / \mathrm{cm}^{3}\right)\end{array}$ & & 2.65 & 2.63 & - \\
\hline $\begin{array}{l}\text { Apparent specific } \\
\text { gravity }\left(\mathrm{g} / \mathrm{cm}^{3}\right)\end{array}$ & & 2.68 & 2.67 & - \\
\hline Fine aggregate & \multirow{4}{*}{$\begin{array}{c}\text { ASTM C } \\
128[15]\end{array}$} & & & - \\
\hline $\begin{array}{l}\text { Bulk specific } \\
\text { gravity }\left(\mathrm{g} / \mathrm{cm}^{3}\right)\end{array}$ & & 2.62 & 2.60 & - \\
\hline $\begin{array}{l}\text { SSD specific } \\
\text { gravity }\left(\mathrm{g} / \mathrm{cm}^{3}\right)\end{array}$ & & 2.65 & 2.62 & - \\
\hline $\begin{array}{l}\text { Apparent specific } \\
\text { gravity }\left(\mathrm{g} / \mathrm{cm}^{3}\right)\end{array}$ & & 2.68 & 2.65 & - \\
\hline $\begin{array}{l}\text { Specific gravity } \\
\text { of filler }\left(\mathrm{g} / \mathrm{cm}^{3}\right)\end{array}$ & $\begin{array}{l}\text { ASTM D } \\
854[16]\end{array}$ & 2.65 & 2.65 & - \\
\hline $\begin{array}{l}\text { Los Angeles } \\
\text { abrasion (\%) }\end{array}$ & $\begin{array}{c}\text { ASTM C } \\
131[17]\end{array}$ & 32 & 22 & $\operatorname{Max} 45$ \\
\hline $\begin{array}{l}\text { Flat and elongated } \\
\text { particles }(\%)\end{array}$ & $\begin{array}{l}\text { ASTM D } \\
4791[18]\end{array}$ & 9 & 6 & $\operatorname{Max} 10$ \\
\hline $\begin{array}{l}\text { Sodium sulfate } \\
\text { soundness (\%) }\end{array}$ & $\begin{array}{l}\text { ASTM C } \\
88[19]\end{array}$ & 7 & 9 & Max 10-20 \\
\hline $\begin{array}{l}\text { Fine aggregate } \\
\text { angularity }\end{array}$ & $\begin{array}{l}\text { ASTM C } \\
1252[20]\end{array}$ & 56.2 & 59.2 & Min 40 \\
\hline
\end{tabular}

Table 3 Properties of base asphalt binders used in this study

\begin{tabular}{ccc}
\hline Value & Standard & Properties \\
\hline 69 & ASTM D5-73 [21] & Penetration $(\mathrm{mm} / 10)$ \\
51 & ASTM D36-76 $[22]$ & Softening point $\left({ }^{\circ} \mathrm{C}\right)$ \\
105 & ASTM D113-79 $[23]$ & Ductility $(\mathrm{cm})$ \\
262 & ASTM D92-78 $[24]$ & Flash point $\left({ }^{\circ} \mathrm{C}\right)$ \\
0.75 & ASTM D1754-78 $[25]$ & Loss of heating $(\%)$ \\
99.5 & ASTM D2042-76 $[26]$ & Trichloroethylene solubility, $(\%)$ \\
\hline
\end{tabular}


a prevalent polymer with high efficiency, and considered to be the most consumed rubber, due to the availability of cheap and abundant raw materials. Therefore, it has the highest volume of production in the rubber industry. Mechanical properties of SBR polymer used in this study have been presented in Table 4.

\subsection{Experiments}

\subsubsection{Asphalt binder modification}

In this study, SBR polymer material was used as an anti-stripping asphalt binder modifier. This material was used at $2 \%$ and $4 \%$ of asphalt binder weight. For the production of modified asphalt binders, the base asphalt binder was first heated to $160^{\circ} \mathrm{C}$ and then the additives were added at the intended percentage. Mixing operation was carried out in the high shear mixer at the rate of $2000 \mathrm{rpm}$ for 15 minutes. The base asphalt binder was placed in the mixer at the same conditions to experience the effect of aging analogous to the modified asphalt binders.

\subsubsection{Mix design}

In the present investigation, the Marshall mix design was utilized according to the AASHTO T245 standard for determination of the optimum asphalt binder percentage. Also, the optimum asphalt binder percentage was assigned based on the MS-2 guideline of Asphalt Institute.

\subsubsection{Repetitive loading test}

Repetitive load test was used to determine the modulus of asphalt mixtures in dry and wet conditions. The AASHTO T283 method was used to expose the specimens under wet conditions. In this study, the indirect tensile $\sigma \varepsilon$ frequency of $1 \mathrm{~Hz}$ under haversine loading with the stress level of $300 \mathrm{kPa}$. The value of the indirect tensile modulus for each mixture in a particular loading cycle can be measured by using Eq. (1).

$$
E^{*}=\frac{\sigma_{\max }}{\varepsilon_{\max }},
$$

where, $\sigma_{\max }$ is the maximum stress for a particular cycle and $\varepsilon_{\max }$ is the corresponding stress in the same cycle.

Modulus ratio for each cycle is obtained according to the Eq. (2) which is considered as an indicator for moisture susceptibility in asphalt mixtures [27]. The greater value for $\mathrm{K}$ means that the strength of the asphalt mixture against the simultaneous effects of traffic and high moisture is greater.
$K=\frac{E_{w e t}^{*}}{E_{d r y}^{*}} \times 100$,

where, $E_{w e t}^{*}$ and $E_{d r y}^{*}$ indicate the indirect tensile modulus value in wet and dry conditions, respectively.

\subsubsection{Measuring the SFE components of aggregate and asphalt binder}

SFE of the materials has been described in several theories according to the molecular structure. An acidic-basic theory is one of the most significant theories which is used extensively for the description of the SFE components of various materials.

A variety of methods can be used to measure the SFE components of asphalt binder and aggregate. Due to the susceptibility of measurement in these experiments, high accurate methods were used according to the reported data in the open literature.

Measuring the SFE components of aggregate

Universal Sorption Device (USD) was used to indirectly measure the SFE components of aggregate using gas adsorption by three solvents. Hence, for the creation of a set of three equations and three unknowns (the three components of the solid matter's SFE), three equations are required. Therefore, it could be noted that three research matters, whose SFE components should be specified, are required for calculation of the SFE components of a solid body. The SFE components for different used materials are reported in Table 5.

Table 4 Mechanical properties of SBR polymer used in this study

\begin{tabular}{lc}
\hline Value & Properties \\
\hline 18 & Tensile Strength $(\mathrm{MPa})$ \\
544 & Elongation at tear $(\%)$ \\
49.2 & Mooney Viscosity $\left(100^{\circ} \mathrm{C}\right)$ \\
-60 & Glass transition temperature $\left({ }^{\circ} \mathrm{C}\right)$ \\
2.7 & Polydispersity \\
9.5 & $\mathrm{pH}$ \\
\hline
\end{tabular}

Table 5 SFE components of the research materials for measuring the SFE components of aggregates $\left(\mathrm{ergs} / \mathrm{cm}^{2}\right)$

\begin{tabular}{lccccc}
\hline $\begin{array}{l}\text { SFE } \\
\text { components }\end{array}$ & $\begin{array}{l}\text { Total } \\
\text { SFE }\end{array}$ & $\begin{array}{c}\text { Lifshitz Van } \\
\text { der Waals }\end{array}$ & Polar & Acidic & Basic \\
\hline n-Hexane & 18.4 & 18.4 & 0 & 0 & 0 \\
$\begin{array}{l}\text { Methyl Propyl } \\
\text { Ketone (MPK) }\end{array}$ & 24.7 & 24.7 & 0 & 0 & 19.6 \\
Water & 72.8 & 21.8 & 51 & 25.5 & 25.5 \\
\hline
\end{tabular}




\section{Measuring SFE components of asphalt binder}

In this section, the Wilhelmy plate technique was used to obtain the contact angle between the asphalt binder and a liquid. This technique is based on the balance of the kinetic forces of a thin plate immersed or pulled out from a liquid at a constant and low speed.

To obtain the passive components, at least three fluids with specified surface energy components are required. In this paper, water, formamide, and glycerin were used due to the relatively large amounts of SFE components, non-miscible with asphalt binder and different amounts of SFE. Their surface energy components have been provided in Table 6.

\section{Results and discussion}

\subsection{Mix design results}

The optimum asphalt binder content in the specimens made of granite and limestone aggregates was 5.5 and $5.8 \%$, respectively. Due to their surface porosity, limestone aggregates absorb more asphalt binder. This causes more optimum asphalt binder content to be absorbed compared to the granite aggregates with fewer pores.

\subsection{Results of the SFE tests}

\subsubsection{Measuring the SFE components of aggregates}

Table 7 indicates the results of measuring the SFE components of aggregates used in the present paper. In all reported cases, the basic components of both aggregates were greater than their acidic components. It is apparent that the ratio of acid to basic component of granite aggregate was higher than limestone aggregate. The non-polar component of limestone and granite aggregates were close to each other, but the polar component of limestone

Table 6 SFE components of the research materials for measuring the SFE components of asphalt binder $\left(\mathrm{ergs} / \mathrm{cm}^{2}\right)$

\begin{tabular}{lccccc}
\hline \multirow{2}{*}{$\begin{array}{l}\text { SFE } \\
\text { components }\end{array}$} & $\begin{array}{c}\text { Total } \\
\text { SFE }\end{array}$ & $\begin{array}{c}\text { Lifshitz Van } \\
\text { der Waals }\end{array}$ & Polar & Acidic & Basic \\
\hline Water & 72.6 & 21.6 & 51 & 25.5 & 25.5 \\
Glycerol & 62.8 & 34 & 28.8 & 3.92 & 57.4 \\
Formamide & 58 & 39 & 19 & 2.28 & 39.6 \\
\hline
\end{tabular}

Table 7 The SFE components of aggregates used in this study

\begin{tabular}{lccccc}
\hline \multirow{2}{*}{$\begin{array}{l}\text { Aggregate } \\
\text { type }\end{array}$} & \multicolumn{5}{c}{ SFE components $\left(\mathrm{ergs} / \mathrm{cm}^{2}\right)$} \\
\hline Limestone & 522.4 & 31.7 & 257.5 & 67.1 & 324.6 \\
Granite & 525.8 & 20.5 & 207.7 & 68.8 & 276.6 \\
\hline
\end{tabular}

aggregate was more than granite aggregate, which led to a significant increase of the total SFE associated with limestone aggregate compared to granite aggregate.

\subsubsection{Measuring the SFE components of the controlled and modified asphalt binders}

Results related to the SFE components of the controlled and modified asphalt binder have been documented in Table 8. It is obvious that the acidic component of the base asphalt binder was higher than its basic component. This caused the asphalt binder to have more acidic properties. Acidic properties of asphalt binder led to the formation of stronger bonds with basic materials such as lime aggregates. The use of SBR polymer increased both the acid and basic components of modified asphalt binders. The percentage increase of the basic component was higher than the acidic component, which resulted in the formation of more basic properties in the SBR modified asphalt binders. An increase in the percentage of this material from $2 \%$ to $4 \%$ also increased the mentioned changes.

Results of Table 8 showed that SBR polymer increased the asphalt binder polar component. The positive or negative impact of this parameter on the asphalt binder-aggregate adhesion could not be stated with certainty. It should be kept in mind that increasing the polar characteristics of asphalt binders leads to increasing the adhesion tendency to polar materials such as aggregate and water.

The results related to a non-polar component of asphalt binder's SFE in Table 8 showed that using SBR polymer increased the non-polar component of modified asphalt binders compared to the base asphalt binder. This led to a formation with stronger non-polar bonds.

The total SFE results showed that using SBR polymer increased this parameter. The increase of the total SFE increased the cohesion free energy. This means that higher energy is required for creation of a certain crack on the asphalt binder film. Increasing the required energy for failure of the asphalt binder film reduced the probability of cohesion failure.

Table 8 SFE components of controlled and modified asphalt binders used in this study

\begin{tabular}{lccccc}
\hline \multirow{2}{*}{$\begin{array}{l}\text { Asphalt binder } \\
\text { type }\end{array}$} & \multicolumn{5}{c}{ SFE components (ergs/cm²) } \\
\hline AC 60/70 & 0.45 & 2.69 & 2.20 & 11.36 & 13.56 \\
$\begin{array}{l}\text { AC 60/70 with } \\
2 \% \text { SBR }\end{array}$ & 0.79 & 2.98 & 3.07 & 12.28 & 15.35 \\
$\begin{array}{l}\text { AC 60/70 with } \\
4 \% \text { SBR }\end{array}$ & 1.03 & 3.27 & 3.67 & 13.84 & 17.51 \\
\hline
\end{tabular}




\subsection{Results of thermodynamic parameters}

Results related to the cohesion free energy parameters, debonding energy, and adhesion free energy have been provided in Figs. 2-4.

A closer look in Fig. 2 shows that using SBR polymer has increased cohesion free energy value. This suggests that higher energy is required for cracking event on the asphalt binder film which reduces the probability of cohesion failure.

Results related to the asphalt binder aggregates adhesion free energy in dry conditions are shown in Fig. 3. This parameter presents the amount of required energy for creation of a failure in asphalt binder-aggregate contact surface. The results suggested that using polymer additives increased the adhesion-free energy of specimens including both kinds of aggregates. It means that more energy is required for separation of the asphalt binder from the aggregate surface. An increase of the percentage of polymer material has led to significant changes in the adhesion-free energy. The amount of adhesion free energy in the specimens made of granite aggregate was greater than limestone aggregate. This suggested that more energy was required to separate the asphalt binder from the granite aggregate surface unit. However, it should be noted that the lime aggregates have a higher specific surface area. This increases the total required energy for separation of the aggregates with more porosity such as limestone.

The free energy of system in the stripping event or the asphalt binder-aggregate adhesion free energy in wet conditions (debonding energy) is the amount of energy released during the stripping process. Given that these values are negative; their absolute values are presented in Fig. 4. According to the principles of thermodynamics, any energizer process is performed spontaneously. Therefore, when water permeates into the binder-aggregate system, the asphalt binder debonding and the stripping event are expected to happen spontaneously. The most important point is that a greater amount of released energy, leads to a greater stripping intensity. The results presented in Fig. 3 showed that using SBR polymer in the specimens made of both types of aggregates reduced the debonding energy. Increasing the percentage of these materials has reduced the value of this parameter. So, increasing the percentage of the polymer material has increased the tendency for stripping. The results showed that more energy was released in the stripping of the compounds made of granite aggregates, which indicated that stripping in the granite aggregate surface unit was more likely to occur.

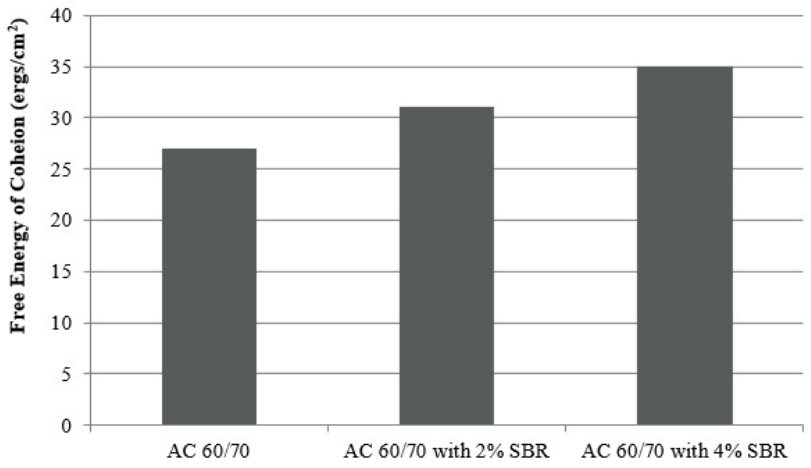

Fig. 2 Cohesion free energy in controlled and modified asphalt binders

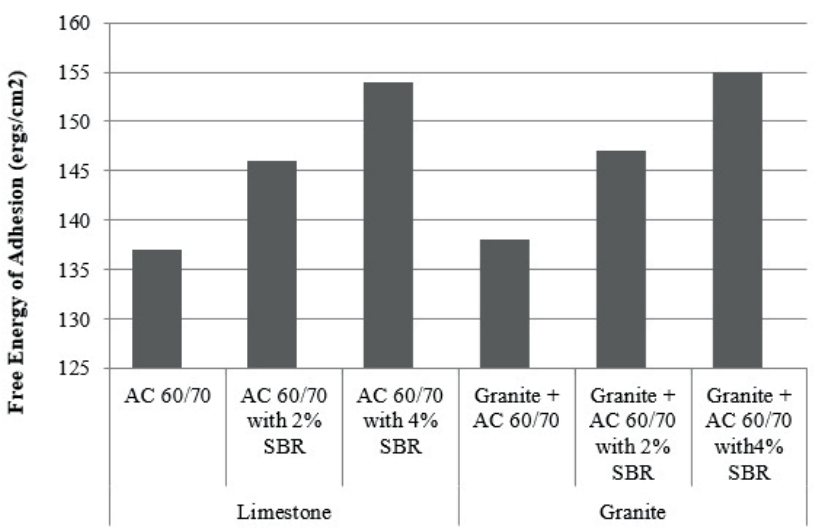

Fig. 3 The asphalt binder-aggregate adhesion free energy under dry conditions

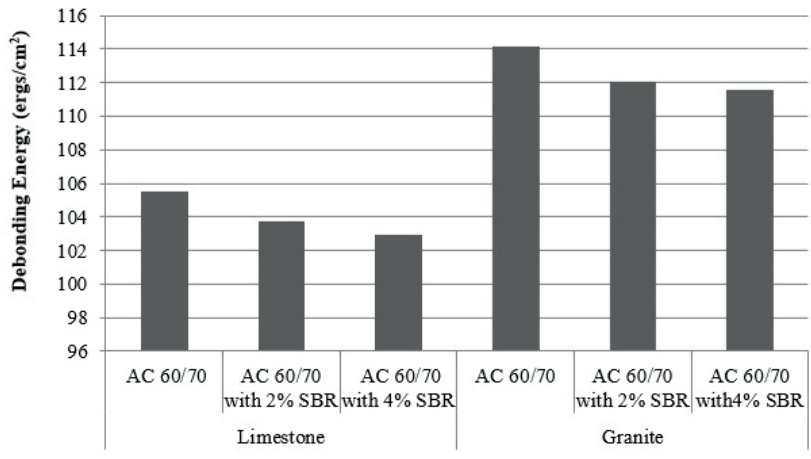

Fig. 4 The asphalt binder-aggregate adhesion free energy under wet conditions

\subsection{Results of the repetitive loading tests}

Repetitive loading test in the wet and dry conditions was conducted on different combinations of asphalt mixtures and the strength modulus of asphalt mixtures in different cycles were obtained. Then, the wet to dry modulus ratio was obtained for each asphalt mixture specimen in each cycle. The results of modulus ratio for the specimens made of limestone and granite aggregates have been provided in Figs. 5-6. The obtained results in Figs. 5-6 shows an obvious effect of using the aggregates, asphalt binders 




Fig. 5 Indirect tensile modulus ratio in samples made of limestone aggregates

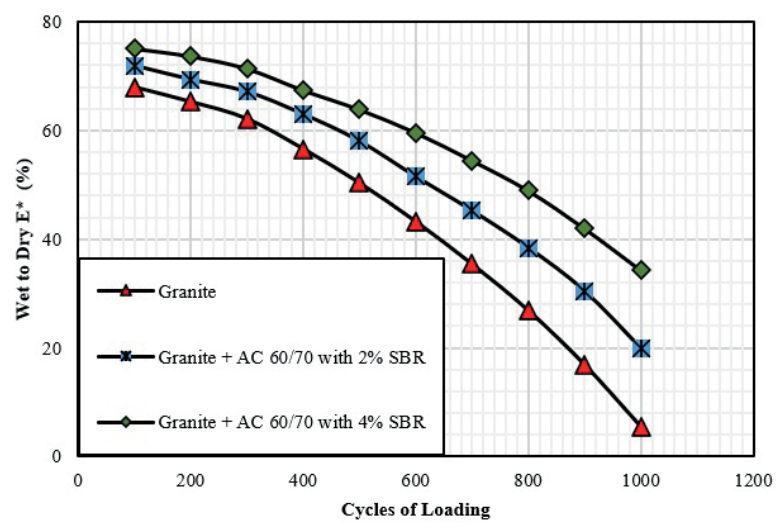

Fig. 6 Indirect tensile modulus ratio in samples made of granite aggregates

and different additives on the moisture damage. Each of these components with mixed features could strengthen or weaken the asphalt mixture against moisture damage.

According to the results obtained in Fig. 5, the specimens made of controlled asphalt binder had the lowest modulus ratio in wet to dry conditions. Using SBR polymer increased the modulus ratio in these specimens. By increasing the percentage of the polymer additive, better performance of asphalt mixture against moisture had become more evident. The difference in the ratio of wet to dry modulus in low loading cycle had become lower between the controlled and modified specimens. As the number of loading cycle increased, this difference also increased. In fact, it can be noted in the controlled specimens, the rate of decrease in the modulus (slope) was greater than the modified specimens.

A similar trend observed in specimens made of limestone aggregate can be seen for the specimens made of granite aggregate. The notable difference is that using SBR additives had made more improvements to the specimens made of granite aggregate. This can be attributed to the reality that the limestone aggregate specimens have higher strength against moisture damage and improvement in their performance hardly occurs in very small amounts.

As was observed in the analysis of SFE method's results, using polymer materials increased cohesion and adhesion free energy in dry conditions. These two events reduced failure in the asphalt binder-aggregate contact surface and asphalt binder film, which increased the strength of the asphalt mixture in loading conditions. As expected, setting the specimens under wet conditions has reduced the strength of asphalt mixture versus loading, because the influence of moisture reduced cohesion in asphalt binder and cause loss of adhesion in asphalt binder-aggregates. All of these factors reduced the strength of asphalt mixture. Using anti-stripping materials improved the strength of asphalt mixture. As mentioned in the previous section, using polymeric materials as an asphalt binder modifier led to reduction of the debonding free energy and a lower tendency of asphalt mixtures for stripping.

\subsubsection{Stripping percentage of the aggregates in loading cycles}

Cheng [28] successfully used the continuous non-linear viscoelastic theory provided by Schapery for material damage for the description of the response of asphalt mixtures under the strain and stress control loading. He applied the Schapery theory which mentioned that damage prediction was validated by repetitive loading tests based on diffusion theory. Thus, the moisture damage of asphalt mixtures is obtained in repetitive loading by calculation of the aggregate surface percentage which is subjected to stripping in different cycles. As can be observed in Eq. (3), the strength ratio (modulus) in wet to dry conditions can be considered to be same as the adhesion ratio between aggregates-asphalt binder in wet and dry conditions.

$\frac{E_{w e t}^{*}}{E_{d r y}^{*}}=\frac{\left[\Delta G_{12} *(1-P)+\Delta G_{132} P\right]}{\left[\Delta G_{12}\right]}$,

where $\Delta G_{12}$ denotes the asphalt binder-aggregate adhesion energy, $\Delta G_{132}$ denotes the asphalt binder-aggregate debonding or system energy in a saturated condition and $P$ is the percentage of the aggregate surface which is subjected to stripping.

For repetitive loading test of stress control, Eq. (3) can be converted to Eq. (4). 


$$
\frac{E_{d r y}^{*}}{E_{\text {wet }}^{*}}=\frac{\left(\frac{\sigma}{\varepsilon}\right)_{d r y}}{\left(\frac{\sigma}{\varepsilon}\right)_{\text {wet }}}=\frac{\varepsilon_{d r y}}{\varepsilon_{\text {wet }}}=\frac{\left[\Delta G_{12}(1-P)+\Delta G_{132} P\right]}{\left[\Delta G_{12}\right]}
$$

All parameters of Eq. (4), except for index $P$, can be obtained from the thermodynamic concepts by measuring the SFE components of asphalt binders and aggregates (Tables 7-8) and wet to dry modulus ratio (Figs. 5-6). Knowing that $P$ is the only thing missing from this equation, it can be calculated and used to determine the stripping trend of aggregate surface from asphalt binders in different loading cycles for various asphalt mixtures.

Results related to asphalt binder stripping percentage from the aggregate surface on the specimens made of granite and limestone aggregates have been depicted in Figs. 7-8, respectively. As a consequence, using polymer additives reduced the asphalt binder stripping percentage from the aggregate's surface in different loading cycles. Moreover, it can be observed that the slope in the

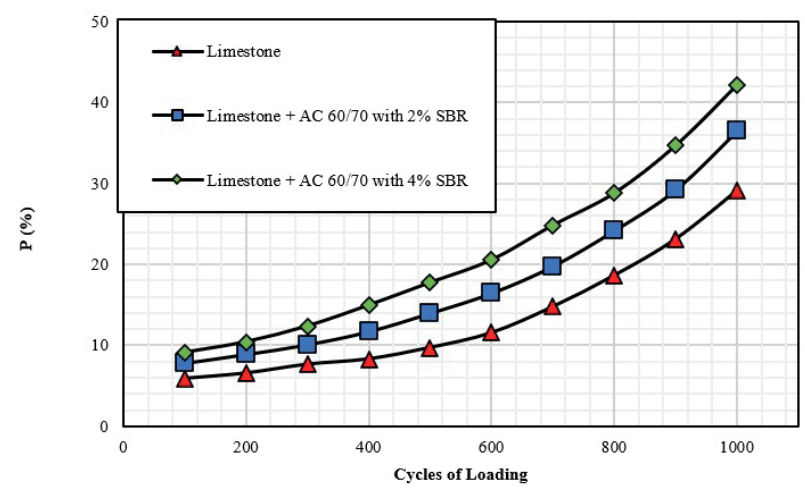

Fig. 7 Stripping percentage of aggregate surface in samples made of limestone aggregates

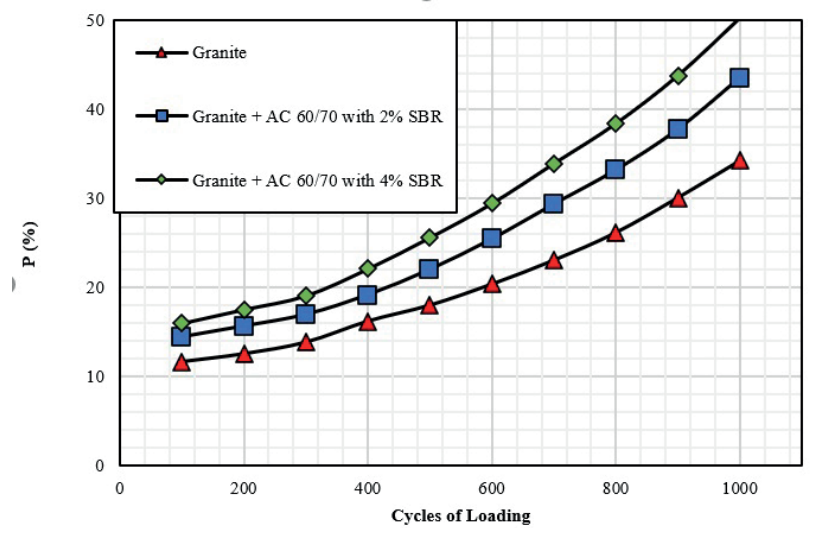

Fig. 8 Stripping percentage of aggregate surface in samples made of granite aggregates stripping percentage against loading cycles chart had an increasing trend. In fact, all aggregates in the primary cycles of loading were attached to the asphalt binder. A higher exposure of specimens to wet conditions and loading frequency lead to a greater percentage of aggregates to be stripped from the asphalt binder. This caused the adhesion reduction and the attached aggregate percentage reduction to intensify each other and therefore, the asphalt binder stripping from the aggregate surface continues with a steeper slope.

It can be observed from Figs. 7-8, that specimens made of limestone aggregates had a higher strength compared to the specimens made of granite aggregates. Different factors were effective in the occurrence of moisture damage and the strength of asphalt mixtures against it. The structure of minerals forming the aggregates used in asphalt mixtures is one of the most significant parameters. Two minerals, $\mathrm{SiO}_{2}$ and $\mathrm{CaO}$ (or $\mathrm{CaCO}_{3}$ ), caused a major change in the hydrophobic or hydrophilic properties of aggregates. A higher percentage of $\mathrm{SiO}_{2}$ mineral indicated that the hydrophilic tendency of aggregates increased and vice versa. Conversely, a higher percentage of the $\mathrm{CaO}$ mineral indicated that the hydrophobic tendency of aggregates increased and vice versa. It can be observed from Table 1 that a large part of granite aggregate was formed by silicon dioxide $\left(\mathrm{SiO}_{2}\right)$ which leads to strong acidic properties. The amount of strong basic parts such as calcium oxide $(\mathrm{CaO})$ in this type of aggregate was much lower than the acidic part. There was hydroxyl groups $(\mathrm{OH})$ on the surface of granite aggregate. These groups $(\mathrm{SiOH})$ form hydrogen bonds with carboxylic acids which were very effective in asphalt binder-aggregates adhesion. But, hydrogen bond easily broke in the presence of water and these two groups were separated and each one produced a hydrogen bond with water molecules. This means that hydrogen bonds formed between molecules of water and $\mathrm{SiOH}$ in aggregates, as well as between water molecules and $\mathrm{COOH}$ in asphalt binders were preferable to the hydrogen bonds between $\mathrm{SiOH}$ in aggregates and $\mathrm{COOH}$ in asphalt binders whose this was easily broken. Conversely, in the case of limestone aggregates, it is observed that the $\mathrm{SiO}_{2}$ mineral percentage is much lesser than the $\mathrm{CaO}$ mineral. In fact, the main reason for the high adhesion strength between limestone aggregates and asphalt binders is caused by the formation of insoluble bonds (covalent) in water that is formed due to the physical reaction between the calcium on the aggregate surface and some functional groups of asphalt binder. 
Other reasons for the better strength of asphalt mixtures made of limestone aggregates include higher asphalt binder-aggregate adhesion, larger specific surface area and less debonding energy in the specimens made by lime aggregates.

\section{Conclusions}

There are several experimental methods for improving the moisture strength of asphalt mixtures. Utilization of anti-stripping materials is the most prevalent method. Executive and Technical problems of the available anti-stripping materials and the technical defects in the moisture susceptibility evaluation methods of asphalt mixtures led to the study of the effect of SBR polymer using mechanical and thermodynamic techniques. The most important experimental results obtained in the present investigation can be noted as:

- Using SBR polymer improved the strength of asphalt mixtures against moisture damage, especially in specimens made of granite aggregates

- Adding SBR polymer increased the cohesion and adhesion free energy and reduced the debonding energy in stripping of specimens containing both types of aggregates, which indicated a decrease in the tendency of the system for stripping.

\section{References}

[1] Sohrabi, M., Shirmohammadi, H., Hamedi, G. H. "Investigating the Effect of Modifying Aggregate Surface by Micronized Calcium Carbonate on Increasing the Moisture Resistance of Asphalt Mixtures", Periodica Polytechnica Civil Engineering, 63(1), pp. 63-76, 2019

https://doi.org/10.3311/PPci.11632

[2] Hamedi, G. H., Azarhoosh, A. R., Khodadadi, M. "Effects of Asphalt Binder Modifying with Polypropylene on Moisture Susceptibility of Asphalt Mixtures with Thermodynamically Concepts", Periodica Polytechnica Civil Engineering, 62(4), pp. 901-910, 2018.

https://doi.org/10.3311/PPci.11570

[3] Choudhary, R., Kumar, A., Murkute, K. "Properties of Waste Polyethylene Terephthalate (PET) Modified Asphalt Mixes: Dependence on PET Size, PET Content, and Mixing Process", Periodica Polytechnica Civil Engineering, 62(3), pp. 685-693, 2018. https://doi.org/10.3311/PPci.10797

[4] Azarhoosh, A. R., Hamedi, G. H., Abandansari, H. F. "Providing Laboratory Rutting Models for Modified Asphalt Mixes with Different Waste Materials", Periodica Polytechnica Civil Engineering, 62(2), pp. 308-317, 2018.

https://doi.org/10.3311/PPci.10684
- The stripping percentage index indicated that the specimens made of controlled asphalt binders in loading cycles under wet conditions were subject to a higher rate of stripping and the falling rate of the loading modulus in them was faster than the modified specimens.

- Using SBR polymer increased both the basic and acidic components of asphalt binders. The percentage of increase in the basic component was higher than the acidic component, which resulted in the formation of more basic properties in the asphalt binders modified by this material.

- Adding SBR polymer increased the polar component of asphalt binder. The positive or negative effect of this parameter on the asphalt binder aggregates adhesion could not be stated with certainty. It should be kept in mind that the increasing the polar characteristics of asphalt binders increased the desire of its adhesion to polar materials such as aggregates and water.

- Using SBR polymer increased the non-polar component of the modified asphalt binders compared to the base asphalt binder. This led to the formation of stronger non-polar bonds.

[5] Bargegol, I., Sakanlou, F., Sohrabi, M., Hamedi, G. H. "Investigating the Effect of Metal Nanomaterials on the Moisture Sensitivity Process of Asphalt Mixes", Periodica Polytechnica Civil Engineering, 65(1), pp. 15-25, 2021. https://doi.org/10.3311/PPci.12223

[6] Hamedi, G. H., Shabani, A., Safargar, Y. "Investigating the Effect of Hydrophobic Additives in Moisture Damage Reduction of Asphalt Mixtures", Periodica Polytechnica Civil Engineering, 64(3), pp. 702-712, 2020.

https://doi.org/10.3311/PPci.15457

[7] Abandansari, H. F., Modarres, A. "Investigating effects of using nanomaterial on moisture susceptibility of hot-mix asphalt using mechanical and thermodynamic methods", Construction and Building Materials, 131, pp. 667-675, 2017.

https://doi.org/10.1016/j.conbuildmat.2016.11.052

[8] Bhasin, A. "Development of methods to quantify bitumen-aggregate adhesion and loss of adhesion due to water", $\mathrm{PhD}$ Dissertation, Texas A\&M University, 2006. [online] Available at: http://hdl.handle.net/1969.1/5934

[9] Howson, J. E. "Relationship Between Surface Free Energy and Total Work of Fracture of Asphalt Binder and Asphalt BinderAggregate Interfaces", PhD Dissertation, Texas A\&M University, 2011. [online] Available at: http://hdl.handle.net/1969.1/ ETD-TAMU-2011-08-10179 
[10] Hamedi, G. H., Moghadas Nejad, F. "Using energy parameters based on the surface free energy concept to evaluate the moisture susceptibility of hot mix asphalt", Road Materials and Pavement Design, 16(2), pp. 239-255, 2015 https://doi.org/10.1080/14680629.2014.990049

[11] Hamedi, G. H., Sohrabi, M., Sakanlou, F., Tahami, S. A. "Investigating the Effect of Various Fillers on Cohesive Failure Mechanism in Asphalt Mixtures", Periodica Polytechnica Civil Engineering, 64(1), pp. 144-155, 2020. https://doi.org/10.3311/PPci.14505

[12] Hamedi, G. H., Moghadas Nejad, F., Oveisi, K. "Investigating the effects of using nanomaterials on moisture damage of HMA", Road Materials and Pavement Design, 16(3), pp. 536-522, 2015. https://oi.org/10.1080/14680629.2015.1020850

[13] Souliman, M. I., Hajj, E. Y., Sebaaly, P. E. "Impact of Antistrip Additives on the Long-Term Aging Rheological Properties of Asphalt Binders", Journal of Materials in Civil Engineering, 27(8), Article ID C4014006, 2015. https://doi.org/10.1061/(ASCE)MT.1943-5533.0001111

[14] ASTM "ASTM C127 - 15 Standard Test Method for Relative Density (Specific Gravity) and Absorption of Coarse Aggregate", ASTM International, West Conshohocken, PA, USA, 2015. https://doi.org/10.1520/C0127-15

[15] ASTM "ASTM C128 - 15 Standard Test Method for Relative Density (Specific Gravity) and Absorption of Fine Aggregate", ASTM International, West Conshohocken, PA, USA, 2015. https://doi.org/10.1520/C0128-15

[16] ASTM "ASTM D854 - 14 Standard Test Methods for Specific Gravity of Soil Solids by Water Pycnometer", ASTM International, West Conshohocken, PA, USA, 2014. https://doi.org/10.1520/D0854-14

[17] ASTM "ASTM C131 - 01 Standard Test Method for Resistance to Degradation of Small-Size Coarse Aggregate by Abrasion and Impact in the Los Angeles Machine", ASTM International, West Conshohocken, PA, USA, 2001. https://doi.org/10.1520/C0131-01
[18] ASTM "ASTM D4791 - 19 Standard Test Method for Flat Particles, Elongated Particles, or Flat and Elongated Particles in Coarse Aggregate", ASTM International, West Conshohocken, PA, USA, 2019. https://doi.org/10.1520/D4791-19

[19] ASTM "ASTM C88 - 13 Standard Test Method for Soundness of Aggregates by Use of Sodium Sulfate or Magnesium Sulfate", ASTM International, West Conshohocken, PA, USA, 2013. https://doi.org/10.1520/C0088-13

[20] ASTM "ASTM C1252 - 17 Standard Test Methods for Uncompacted Void Content of Fine Aggregate (as Influenced by Particle Shape, Surface Texture, and Grading)", ASTM International, West Conshohocken, PA, USA, 2017. https://doi.org/10.1520/C1252-17

[21] ASTM "ASTM D5 - 73(1978) Standard Test Method for Penetration Of Bituminous Materials", ASTM International, West Conshohocken, PA, USA, 1978.

[22] ASTM "ASTM D36 - 76 Standard Test Method for Softening Point Of Bitumen (Ring-And-Ball Apparatus)", ASTM International, West Conshohocken, PA, USA, 1976.

[23] ASTM "ASTM D113 - 79 Standard Test Method for Ductility of Asphalt Materials", ASTM International, West Conshohocken, PA, USA, 1979.

[24] ASTM "ASTM D92 - 78 Standard Test Method for Flash and Fire Points by Cleveland Open Cup Tester", ASTM International, West Conshohocken, PA, USA, 1978.

[25] ASTM "ASTM D1754 - 78 Standard Test Method for Effects of Heat and Air on Asphaltic Materials (Thin-Film Oven Test)", ASTM International, West Conshohocken, PA, USA, 1978.

[26] ASTM "ASTM D2042 - 76 Standard Test Method for Solubility of Asphalt Materials in Trichloroethylene", ASTM International, West Conshohocken, PA, USA, 1976.

[27] Shah, B. D. "Evaluation of moisture damage within asphalt concrete mixes", MSc Dissertation, Texas A\&M University, 2004. [online] Available at: http://hdl.handle.net/1969.1/209

[28] Cheng, D. "Surface free energy of asphalt-aggregate system and performance analysis of asphalt concrete based on surface free energy", PhD Dissertation, Texas A\&M University, 2003. 